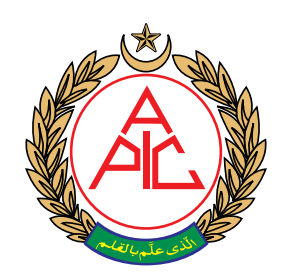

\title{
Knowledge, training and practice of cricoid pressure application by the anesthesiologists of teaching hospitals of a developing country: A national survey
}

\author{
Mohsin Nazir Butt, FCPS ${ }^{1}$, Muhammad Qamarul Hoda, FFARCSI ${ }^{2}$
}

\author{
${ }^{1}$ Assistant Professor, \\ 2Professor, Department of \\ Anesthesiology, Aga Khan \\ University Hospital Karachi, \\ (Pakistan)

\section{Correspondence:} \\ Dr. Mohsin Nazir Butt ${ }^{1}$ \\ Department of Anesthesiology, \\ Private Wing, Second Floor, \\ Aga Khan University Hospital, \\ Stadium Road, P.O. Box 3500, \\ Karachi 74800, (Pakistan). \\ Mobile: 00923212227083, \\ 00923343090439 \\ Phone: 00922134864637 \\ E-mail: mohsin.nazir@aku.edu \\ Received: 4 March 2019, \\ Reviewed: 22 March, 6 April \\ 2019, \\ Accepted: 21 May 2019
}

\begin{abstract}
Objective: To assess the knowledge, training and practices of cricoid pressure (CP) application among the anesthesiologists working in teaching hospitals of a developing country.
\end{abstract}

\begin{abstract}
Methodology: This cross sectional study was conducted among the consultant anesthesiologists and anesthesia trainees with at least 18 months of anesthesia experience, working in teaching hospitals of four provinces of the country and one teaching hospital of the capital city. The survey was conducted through a validated questionnaire including questions regarding knowledge, training and practice of $C P$ application among anesthesiologist working in teaching hospitals of the capital city and four provinces of Pakistan.
\end{abstract}

Results: A total of 220 questionnaires were distributed, 212 were returned with a response rate of $96 \% .36$ (16.98\%) participants made correct answers to all of the six 'knowledge' based questions. With respect to "training", 116 participants $(55.50 \%)$ responded that they had supervised instructions on anesthetized patients, 19 participants (9.1\%) had training courses using manikins and 74 participants (35.4\%) had received knowledge from books only. 210 participants responded to the questions regarding the "practice" of CP application. 197 participants (93.8\%) routine practice CP.

Conclusion: Based on our survey, the 'knowledge' of cricoid pressure application was poor among the anesthesiologists working in teaching hospitals. There are insufficient training opportunities for this important anesthesia related skill. More specific education and simulation based training should be made mandatory for enhancing clinical use of cricoid pressure.

Key words: Cricoid pressure; Anesthesiologist; Rapid sequence induction

Citation: Butt MN, Hoda MQ. Knowledge, training and practice of cricoid pressure application by the anesthesiologists of teaching hospitals of a developing country: A national survey. Anaesth. pain \& intensive care 2019;23(2):151-156

\section{INTRODUCTION}

Cricoid pressure $(\mathrm{CP})$ is a technique used to reduce the risk of the aspiration of stomach contents during induction of general anesthesia. The cricoid cartilage is pushed against the body of the sixth cervical vertebra; it compresses the esophagus to prevent passive regurgitation. This technique of applying $\mathrm{CP}$ cannot stop the active vomiting. ${ }^{1}$ It is most commonly used during rapid sequence induction (RSI) to prevent pulmonary aspiration of gastric and esophageal contents among full stomach patients. ${ }^{2} \mathrm{CP}$ was first described by Monro in 1774, when he used it in drowning victims to prevent gastric distention. ${ }^{3}$ This maneuver was later on described by Sellick in $1961 .{ }^{4}$ Sellick described the technique of correctly applying 
the CP. Brian Sellick studied a simple method of preventing regurgitation and aspiration of stomach contents in cadaver. ${ }^{5}$ The description of applying CP by Sellicks was very simple and precise. According to the Sellick, before induction of anesthesia the cricoid cartilage is palpated and lightly held between the thumb and second finger of the same hand, as induction of anesthesia begins, pressure is exerted on the cricoid cartilage by index finger. A firm pressure is applied without obstructing the patient's airway until the successful endotracheal intubation and cuff inflation is completed. ${ }^{5}$

In the last two decades, clinicians have questioned about the efficacy of CP and necessity of this maneuver. Some clinicians have suggested abandoning it due to the reason that the esophagus is not exactly posterior to the cricoid cartilage and therefore applying pressure on cricoid cartilage does not reliably occlude the esophagus. Some have also suggested that it makes tracheal intubation more difficult and also induces relaxation of esophageal sphincter. ${ }^{3}$ On the other hand, in case of regurgitation and pulmonary aspiration the extremely grave consequences, ranging from aspiration pneumonitis, lung damage, acute respiratory distress syndrome(ARDS) to death within a very brief period of critical illness should also kept in mind. Despite controversy regarding effectiveness of CP and its safety, it remains standard practice of most anesthesiologists ${ }^{6}$ and recommended by recent difficult airway society 2015 guidelines (DAS) during rapid sequence induction. ${ }^{7}$

Improperly applied CP could cause distortion of the airway, make intubation more difficult, and contribute to significant morbidity ${ }^{2}$. Different surveys conducted among the anesthesiologists of UK, USA and Sweden showed a uniform poor theoretical knowledge and variation in performance of this maneuver. ${ }^{6}$ Such type of survey has not been conducted in Pakistan. The aim of this survey was to assess the knowledge, practices trends and training patterns of CP application among the anesthesiologists working in teaching hospitals of Pakistan.

\section{METHODOLOGY}

After the approval of departmental anesthesia research committee and institutional ethical review committee (ERC); a national survey was conducted among the consultant and trainee anesthesiologists with at least 18 months of anesthesia experience and currently working in teaching hospitals of the country. It was an analytical cross sectional survey conducted for a period of six months, from April 2016 to October 2016. Sampling of teaching hospitals of entire country was conducted through cluster sampling technique. For cluster sampling; initially, a complete list of teaching hospitals of the country was prepared. A total of five clusters were made, one corresponded to the capital city of the country and four clusters were corresponded to four provinces of the country. From each cluster, teaching hospitals were chosen through random sampling. A total of nine teaching hospitals of the country were finally selected for data collection. Later on, a complete list of anesthesiologists and trainees working in those selected hospitals was prepared and selected anesthesiologists were sent written consent forms for participation in that survey through e-mail. Those who gave consent, survey questionnaires were sent to them. Assuming that $50 \%$ participants have knowledge and training about CP within 7\% level of precision and $95 \%$ confidence interval, a minimum of 200 participants were required for that survey. After adjusting for anticipated reduced response rate, a total of 220 questionnaires were sent to the trainees and consultant anesthesiologists. Each survey questionnaire (table $1 \& 2$ ) has two sections i.e. section $\mathrm{A}$ and section B. Sections A included six questions regarding "knowledge" of $\mathrm{CP}$ application, and two questions regarding "training" of CP application. Section B included six questions regarding the "practice of CP application". The questionnaire used in the survey was prepared by selecting questions from previously used validated questionnaires in different studies related to $\mathrm{CP}$ application. These questionnaires were circulated through e-mails to the individuals and by post to their hospitals addresses and by hand to all of the remaining participants, who attended the two national anesthesia conferences organized by the national society of anesthesiology and one anesthesia continuous medical education (CME) sessions held in year 2016. All of the consultant anesthesiologists and anesthesia trainees were requested to fill in the questionnaire anonymously and return it back by post or by hand. The responses to the questionnaires were collected by investigators themselves \& one study data collector. The information from hard copies of anonymous survey questionnaire were entered in Microsoft excel. The data was kept confidential. Only primary investigator and data analyst had access to the data.

The data was exported to SPSS version 20.0 software for analysis. The responses of the participants were categorized into three sections; "knowledge", "training" and "practice". Baseline characteristics of the participants were described as frequencies and percentages for qualitative variables like gender and designation, the quantitative variable like years of experience was described as mean \pm standard deviation. Frequency and percentages of the responses to each section were estimated. Then the "correct" answers of each section were also summarized into frequencies and percentages. The practice of $\mathrm{CP}$ 
original article

was analyzed against different pattern of learning using chi square test. $P$ value of less than 0.05 was considered statistically significant.

\section{RESULTS}

A total of 220 questionnaires were distributed and 212 were returned with a response rate of about $96 \%$. Out of 212 participants, $143(67.5 \%)$ were male and 69(32.2\%) were female anesthesiologists. Among the respondents 90 participants $(42.4 \%)$ were anesthesia trainees and 120 participants $(56.6 \%)$ were anesthesia consultants and two participants $(0.94 \%)$ did not mention their designations. The mean \pm standard deviation (SD) year of experience among anesthesia consultants was $13.29 \pm 9.53$ years and among anesthesia trainee was $3.9 \pm 2.45$ years.

Among the 212 respondents, 36 (16.98\%) who made correct answers to all of the six "knowledge" based questions, 80 participants (37.73\%) made five out of six correct answers while remaining 96 participants $(45.29 \%)$ made correct answers to less than five knowledge based questions. The details of responses to each Knowledge based questions are given in (Table 1).

210 participants responded the questions regarding the "practice" of CP application. 168 (80\%) participants routinely practice $\mathrm{CP}$ to all full stomach patients. The responses are summarized in the Table 2.

In response to the answers regarding the "training" of CP application, 209 participants responded to these questions. $116(55.50 \%)$ had supervised instructions on anesthetized patients, 19 (9.1\%) had training courses using manikins and $74(35.4 \%)$ had knowledge from books only, and then practiced on patients (Figure 1).

208 participants responded to question regarding the "time since formal training" of CP application. 109 participants (52.4\%) had more than two
Table 1: Assessment of responded knowledge as per questions $(n=$ 212)

\begin{tabular}{|c|c|c|}
\hline Questions & $\begin{array}{l}\text { Correct } \\
\text { response }\end{array}$ & $\begin{array}{l}\text { Incorrect } \\
\text { response }\end{array}$ \\
\hline $\begin{array}{l}\text { 1. Cricoid pressure is applied to which of the following? (2) } \\
\text { a. Thyroid cartilage } \\
\text { b. Thyroid \& cricoid cartilage } \\
\text { c. Cricoid cartilage } \\
\text { d. Front of Neck } \\
\text { e. Tracheal rings }\end{array}$ & $\begin{array}{c}202 \\
(95.3 \%)\end{array}$ & $10(4.7 \%)$ \\
\hline $\begin{array}{l}\text { 2. When do you start applying cricoid pressure? (6) } \\
\text { a. Before induction of } \\
\text { Anaesthesia } \\
\text { b. At Induction of Anaesthesia } \\
\text { c. After muscle relaxant } \\
\text { administration } \\
\text { d. No comment }\end{array}$ & $\begin{array}{c}138 \\
(65.1 \%)\end{array}$ & 74 (34.9\%) \\
\hline $\begin{array}{l}\text { 3. Do you routinely bag-mask ventilates the patients before } \\
\text { intubation while applying cricoid pressure? (6) } \\
\text { a. Yes } \\
\text { b. No } \\
\text { c. Don't remember }\end{array}$ & $\begin{array}{c}155 \\
(73.1 \%)\end{array}$ & $57(26.9 \%)$ \\
\hline $\begin{array}{l}\text { 4. How much force should be applied while giving cricoid } \\
\text { pressure? (6) } \\
\text { a. } 10-20 \mathrm{~N} \\
\text { b. } 20-30 \mathrm{~N} \\
\text { c. } 40-60 \mathrm{~N} \\
\text { d. } 30-40 \mathrm{~N}\end{array}$ & $76(35.8 \%)$ & $\begin{array}{c}136 \\
(64.2 \%)\end{array}$ \\
\hline $\begin{array}{l}\text { 5. When do you release cricoid pressure? (2) } \\
\text { a. When laryngosc } \\
\text { ope is removed } \\
\text { b. Just after intubation } \\
\text { c. After confirmation and ETT cuff } \\
\text { inflation } \\
\text { d. No comment }\end{array}$ & $\begin{array}{c}179 \\
(84.4 \%)\end{array}$ & $33(15.6 \%)$ \\
\hline $\begin{array}{l}\text { 6. The purpose of applying cricoid pressure is to (2) } \\
\text { a. Improve the view during } \\
\text { laryngoscopy } \\
\text { b. Prevent vomiting during } \\
\text { induction of Anaesthesia } \\
\text { c. Prevent regurgitation and } \\
\text { aspiration } \\
\text { d. Help insertion of Intubating } \\
\text { laryngeal mask airway }\end{array}$ & $\begin{array}{c}186 \\
(87.7 \%)\end{array}$ & $26(12.3 \%)$ \\
\hline
\end{tabular}

Results are presented as $n$ (\%) [Correct Answer: 1. C, 2. B, 3. B, 4. B, 5. C, 6. C]
Table 2: Practice of cricoid pressure application $(n=210)$

\begin{tabular}{l|c|c|c}
\hline \multicolumn{1}{c|}{ Questions regarding practice of cricoid pressure application } & \multicolumn{3}{|c}{ Responses } \\
\cline { 2 - 4 } Have you ever applied cricoid pressure? (6) & No & $\begin{array}{c}\text { No } \\
\text { Comment }\end{array}$ \\
\hline Do you routinely apply cricoid pressure to all full stomach patients? (6) & $168(80 \%)$ & $32(15.2 \%)$ & $10(4.8 \%)$ \\
\hline Do you remove nasogastric tube before rapid sequence intubation? (6) & $35(16.7 \%)$ & $162(77.1 \%)$ & $13(6.2 \%)$ \\
\hline Do you aspirate nasogastric tube before rapid sequence intubation? (6) & $184(87.6 \%)$ & $22(10.5 \%)$ & $1(0.5 \%)$ \\
\hline $\begin{array}{l}\text { Do you feel difficulty in intubation with improper application of cricoid } \\
\text { pressure (CP)? (6) }\end{array}$ & $179(85.2 \%)$ & $22(10.5 \%)$ & $9(4.3 \%)$ \\
\hline
\end{tabular}

Results are presented as $n$ (\%) 


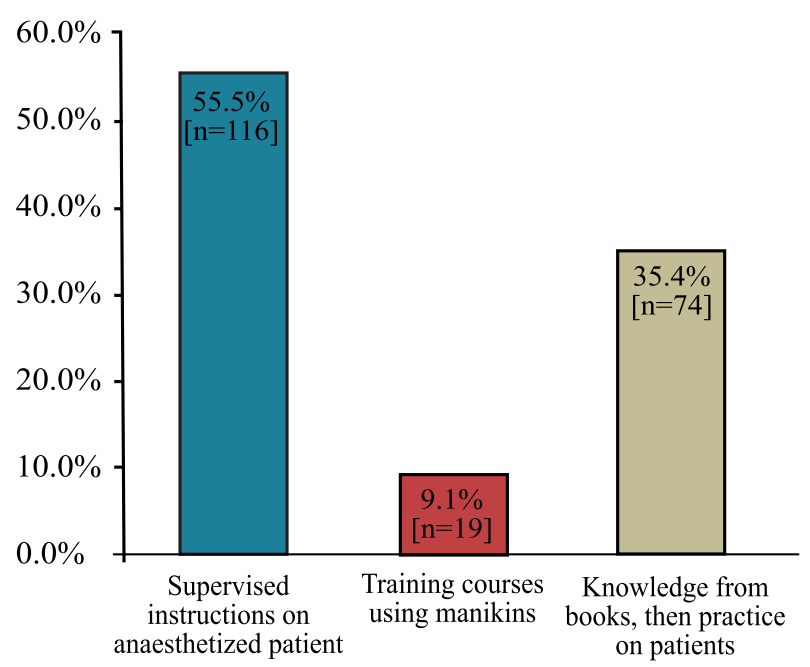

Figure 1: Training in application of CP
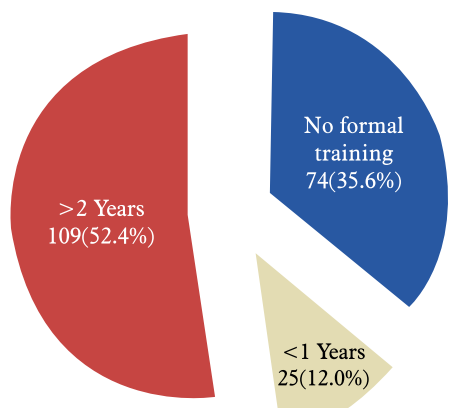

Figure 2: Time since formal training of correct application of $\mathrm{CP}$

years after the formal training of $\mathrm{CP}$ application, 25 participants (12.01\%) had less than 12 months' duration since training and 74 participants $(35.5 \%)$ had no formal training (Figure 2).

In response to question; who applies $\mathrm{CP}$ in your hospital? In most of the teaching hospitals, anesthesia technicians were assigned to apply $\mathrm{CP}$ while endotracheal intubation (Figure 3).

The association of "methods of training" to the "practice of applying CP" were analyzed through crosstab the results, which showed that those who received formal training were significantly more in

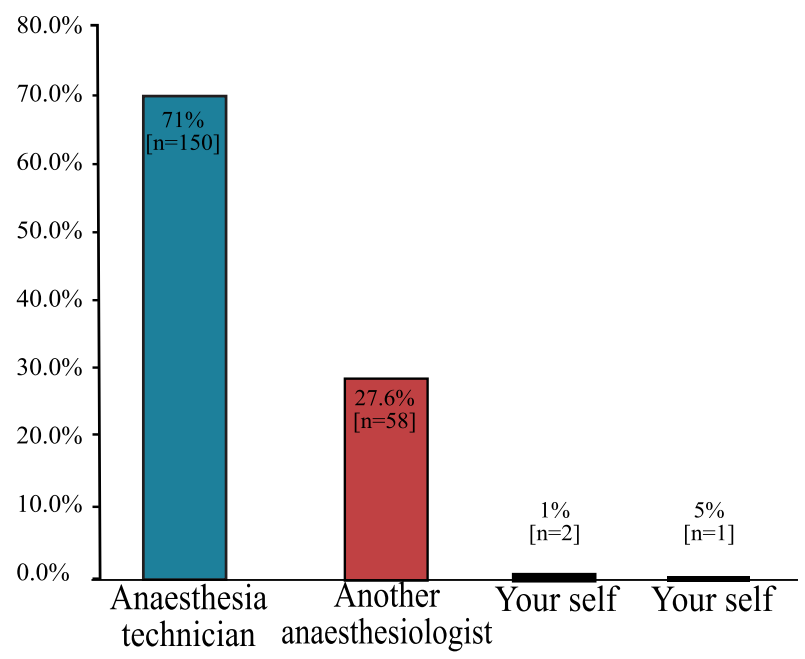

Figure 3: Healthcare professionals employed to apply CP

practicing routine $\mathrm{CP}$ application as compared to their counterparts who did not (Table 3). Subgroup analysis showed that "supervised instruction on anesthetized patient" was significantly effective for routine practice of $\mathrm{CP}$ application as compared to the "knowledge from books" $(\mathrm{P}=0.020)$. When "training courses on manikins" were compared with "supervised instruction on anesthetized patient" and "knowledge from books", it was statistically insignificant $(\mathrm{P}=0.41$ and $\mathrm{P}=0.11$ respectively).

Other practice based questions were also analyzed on the same teaching and training patterns (Table 3 ).

\section{DISCUSSION}

This survey was conducted among anesthesia trainees and consultants working in the teaching hospitals of all four provinces and capital city of the country. We found a good response rate of the survey i.e. $96 \%$. It generally showed a good proportion of practicing physicians $(80 \%)$ while a poor theoretical knowledge of $\mathrm{CP}$ was found among anesthesia personnel. Different types of survey related to the CP application have been done in different parts of the world. In 2007, a survey was conducted among 360 anesthesiologists of India by Krishnan BS et al., which showed a uniform

Table 3: Training and practice of cricoid pressure application

\begin{tabular}{l|c|c|c|c|c|}
\multirow{2}{*}{$\begin{array}{c}\text { Routinely Practice } \\
\text { Cricoid pressure }\end{array}$} & $\begin{array}{c}\text { Supervised instructions on } \\
\text { anaesthetized patient }\end{array}$ & $\begin{array}{c}\text { Training courses } \\
\text { using manikins }\end{array}$ & $\begin{array}{c}\text { Knowledge from books, } \\
\text { then practice on patients }\end{array}$ & \multirow{2}{*}{ Total } & p-Value \\
\cline { 2 - 5 } Yes & $112(96.6 \%)$ & $19(100.0 \%)$ & $65(87.8 \%)$ & 196 & $(93.8 \%)$ \\
\hline No & $4(3.4 \%)$ & $0(0 \%)$ & $9(12.2 \%)$ & $13(6.2 \%)$ & 0.026 \\
\hline Total & 116 & 19 & 74 & 209 & \\
\hline
\end{tabular}


lack of knowledge in most of the participants and a wide variation of practice patterns. ${ }^{6}$ It also showed that irrespective of the number of years of experience, there was a definite need of improvement in formal teaching of anesthesia skills like CP application. A survey was conducted in 2009 among the personnel of emergency department at large teaching hospitals of USA, concluded an overall poor theoretical knowledge among the emergency room staff which could lead to poor application of $\mathrm{CP}^{2}$ Our survey also showed the similar results with insufficient knowledge and varying practices among anesthesiologists of different levels of experience. One of the surveys conducted in anesthesiologists of Southern Sweden by Schmidt A. et al. related to the knowledge and practice of $\mathrm{CP}^{7}$ emphasized the practice of applied force for $\mathrm{CP}$ in laryngotracheal model by different anesthesia personnel with both dominant and non-dominant hands. It showed that there were no significant differences between dominant and non-dominant hands of personnel and about $69 \%$ had no knowledge about the recommended level of force to be applied. In our survey, about $36 \%$ of the participants had correct knowledge of recommended 'force' during CP. We, however, did not study the difference in force of CP by dominant and non-dominant hands of the practitioners.

The results of our survey showed correct answers to all knowledge based questions by only $17 \%$ of total participants. Our survey was the first national survey conducted related to $\mathrm{CP}$, it has also highlighted an important aspect regarding the training opportunities for anesthesia related skills including CP application. We found that $35.4 \%$ participants had knowledge from book only and then practiced on patients; they had no formal training of CP application through manikins or laryngo-tracheal models. This showed an unsafe practice of learning a skill that might be potentially very helpful in preventing the aspiration of gastric contents among the high risk patients. Our results also emphasized the need for specialized, formal and well-structured training of anesthesia and related skills in most of the teaching hospitals of the country. In our survey, different types of teaching and training patterns showed that the anesthesiologists who had different teaching or trainings methods including supervised instruction on anesthetized patients, training courses on manikins and knowledge from books and applied to the patients. The study done in Sweden in $2001,{ }^{8}$ concluded that more specific education and training is mandatory for improving clinical use of $\mathrm{CP}$ and in turn improve patients' safety. They recommended that 'simulation training' and 'standardized evaluation procedures' should be included in future training programs. A study related to the simulator training, conducted by Meek $\mathrm{T}$ and colleagues concluded that the performance of $\mathrm{CP}$ was improved by practical training on a simulator. ${ }^{9}$ Does regular training and assessment of $\mathrm{CP}$ application can make any difference in the overall results of correct application? In relation to the previously stated question, it has been described in a study that a single training session on manikins can significantly improve the performance. ${ }^{10}$ The ability of training participants of correctly applying the CP and appropriate force has been seen to be retained by about $72 \%$ of anesthesia personnel for 14 to 21 days after a single training session. ${ }^{6}$. The ability to learn the recommended amount of CP by anesthesia personnel and the ability to retain this knowledge is about three months. ${ }^{11}$ It has been suggested that simulation trainings are required every three to six months by the anesthesia personnel to refresh their knowledge and practice of CP application. ${ }^{6}$

\section{Strengths:}

To our knowledge, this is the first survey conducted at national level in Pakistan. In this survey the qualified anesthesiologist and anesthesia trainees from all over Pakistan were approached. The response rate of this survey was very high. In this survey we used cluster sampling techniques to randomly cover the anesthesiologists working in the teaching hospitals of all four provinces of Pakistan along with the teaching hospital of the capital city Islamabad.

\section{LIMITATIONS}

There might be some information bias in the questionnaires returned after repeated reminders, as these might be having some artificially inflated correct answers and few missing information like their designations. The response rate for questionnaires were sent by post was lower. In this cross sectional survey, we did not study the difference in knowledge, practice and applied force of CP by different subgroups like 'trainees and consultants', 'male or female participants' and 'dominant or nondominant hands' of participants.

\section{CONCLUSION}

On the basis of the survey results, we can conclude that most of the anesthesiologists in Pakistan routinely practice cricoid pressure for full stomach patients.

The knowledge of cricoid pressure application was poor uniformly among the anesthesiologist working in teaching hospitals of Pakistan. There are insufficient formal training opportunities by simulation for the anesthesia related skill in most of the teaching hospitals of Pakistan. More specific education and simulation training are required for improving clinical use of cricoid pressure and it may result in enhancing the patientcare during surgeries 
with full stomach.

\section{Acknowledgements:}

- $\quad$ Dr. Mujahid ul Islam, Consultant Anesthesiologist, North West General Hospital Peshawar, (Pakistan) for his contribution in data collection from Khyber Pakhtunkhwa province.

- $\quad$ Professor Amjad, Department of Anesthesiology, Bolan Medical College Hospital Quetta, (Pakistan) for his contribution in data collection from Baluchistan province.

- Dr. Hayat Shams, Senior Instructor, Department of Anesthesiology, Aga Khan University Hospital Karachi, (Pakistan).for his contribution in data collection from Shifa
International Hospital, Islamabad, (Pakistan)

- Mr. Amir Raza, Research Coordinator, Mrs. Feroza Nazir, Research Associate and Miss Nausheen Abbas, Research Assistant, Department of Anesthesiology, for their contribution in data analysis

Conflict of interest: None.

\section{Authors' contribution:}

MNB: designing the study, literature search, drafting manuscript, data collection, data entry, analysis and interpretation of data,

$\mathrm{MQH}$ : Conceptualization of the study, data collection, interpretation of results, critical review of intellectual content.

\section{REFERENCES}

1. Harris P, Nagy S, Vardaxis N. Mosby's Dictionary of Medicine, Nursing and Health Professions-Australian \& New Zealand Edition-eBook. Elsevier Health Sciences 2014 Sep 8.

2. Nafiu 00, Bradin S, Tremper KK. Knowledge, attitude, and practice regarding cricoid pressure of ED personnel at a large US teaching hospital. J Emerg Nurs. 2009;35:115. [PubMed]

3. Bhatia N, Bhagat H, Sen I. Cricoid pressure: Where do we stand? $J$ Anaesthesiol Clin Pharmacol. 2014;30:3. [PubMed] [Free full text] DOI: $10.4103 / 0970-9185.125683$

4. Nikandish R, Shahbazi S, Zand F, Jamshidi H. A Survey on Cricoid Pressure Application by Anesthetists.
Shiraz E-Med Jr. 2007;8:120-6.

5. Baskett PJ, Baskett TF. Brian Sellick, cricoid pressure and the Sellick manoeuvre. Resuscitation. 2004;61:5-7. [PubMed]

6. Krishnan B, Sanjib D, Harikrishna D, Rajlakshmi B, Korula G. Cricoid pressure: a survey of its practice in India. Indian J Anaesth. 2007;51:505.

7. Frerk C, Mitchell V, McNarry A, Mendonca C, Bhagrath R, Patel A, et al. Difficult Airway Society 2015 guidelines for management of unanticipated difficult intubation in adults. Br J Anesth 2015;115:827-48. [PubMed] [Free full text] D0l:10.1093/ bja/aev371

8. Schmidt A, Åkeson J. Practice and knowledge of cricoid pressure in southern Sweden. Acta Anaesthesiolo
Scand. 2001;45:1210-4. [PubMed]

9. Meek T, Gittins N, Duggan J. Cricoid pressure: knowledge and performance amongst anaesthetic assistants. Anaesthesia. 1999;54:5962. [PubMed]

10. Vanner R, Pryle B. Regurgitation and oesophageal rupture with cricoid pressure: acadaverstudy. Anaesthesia. 1992 47;732-5. [PubMed] DOI:10.1111/j.1365-2044.1992. tb03248.x

11. Herman NL, Carter B, Van Decar TK. Cricoid pressure: teaching the recommended level. Anesth Analg. 1996;83:859-63. [PubMed] DOl: 10.1097/00000539-19961000000036 